\title{
La reprise des divisions cellulaires dans l'œuf fécondé est due à l'activation par le calcium de la protéine kinase de type II dépendante de la calmoduline
}

Au cours de la maturation méiotique et de l'embryogenèse précoce, le cycle cellulaire est contrôlé par les variations d'activité de MPF (maturation/mitosis promoting factor, $[1,2])$, un complexe entre la protéine kinase p34 calc2 et une cycline de type B. ('hez les vertébrés, le cycle cellulaire des ceufs non fécondés est arrêté en métaphase du second cycle méiotique par un facteur cytostatique (CSF : cytostatic factor) dont l'activité est contrôlée par le produit du gène cellulaire c-mos, équivalent de l'oncogène v-mos du virus du sarcome murin de Moloney [3]. L'arrêt du cycle cellulaire en métaphase est dû à l'incapacité des œufs non fécondés de dégrader les cyclines mitotiques, et donc d'inactiver MPF. L'inactivation périodique de MPF est en effet due à la dégradation de sa sous-unité cycline par un mécanisme protéolytique dépendant de l'ubiquitine, dont la particularité est de n'être activé qu'à la transition métaphase-anaphase... par MPF lui-même [4]. (''est cette aptitude de MPF à programmer sa propre inactivation qui lui confère son rôle d'horloge rythmant les cycles cellulaires rudimentaires (sans phases ('I ni G2) de l'embry'ogenèse précoce. La fécondation (ou l'activation parthénogénétique) provoque une augmentation transitoire de la pageant comme une vague parcourant l'œuf en quelques secondes, à partir du point de pénétration du spermatozoïde (ou du point d'activation). ('ette vague calcique, responsable de l'inactivation de C.SF et de MPF, permet la reprise du cycle cellulaire et le démarrage du développement embryonnaire.

Il avait été proposé (voir $\mathrm{m} / \mathrm{s} n^{\circ} 2$, vol 6, p. 162) que le ( a $^{2+}$ provoquait la destruction de c-Mos par la calpaïne, une protéase activée par le ('a ${ }^{2+}$, levant ainsi le blocage exercé par (SSF sur la dégradation des cyclines [5]. Il vient d'être démontré que la vague calcique accompagnant la fécondation agit en fait par l'intermédiaire de la protéine kinase de type II dépendante de la calmoduline $\left(\mathrm{CaMK}_{\mathrm{II}}\right)$, et non de la calpaïne [6].

La (aMK II $_{\text {I }}$ peut être rendue indépendante du ( $\mathrm{a}^{2+}$ et de la calmoduline, donc constitutivement active, par ablation de sa partie Nterminale, contenant un domaine auto-inhibiteur (fragment 281-303). La micro-injection de cette $\mathrm{CaMK}_{\mathrm{II}}$ tronquée provoque, même en absence de $\mathrm{C}^{2+}{ }^{2+}$, l'activation parthénogénétique de l'œuf, elle-même corrélée à l'inactivation de MPF et CSF. En outre, elle déclenche la dégradation des cyclines mitotiques dans des extraits réalisés à partir d'œufs non fécondés, contrairement à la protéine non tronquée, inefficace en absence de $\mathrm{Ca}^{2+}$. Bien sûr, la dégradation des cyclines peut également être déclenchée par addition de $\mathrm{Ca}^{2+}$, qui active la $\mathrm{CaMK}_{\mathrm{II}}$ endogène des extraits. Toutefois, cette dégradation peut être bloquée par addition d'un peptide (MLC:K [791-814]), dérivé lui-même d'une autre kinase dépendante de la calmoduline qui phosphoryle les chaînes légères de la myosine (MLC.K myosin light chain kinase). ('e peptide, antagoniste de la calmoduline, bloque la dégradation des cyclines provoquée par le $\mathrm{C}^{2}{ }^{2+}$, mais est sans effet sur la dégradation provoquée par la ('a.MK $\mathrm{II}_{\mathrm{I}}$ tronquée et constitutivement active. Comme on pouvait s'y attendre, le peptide autoinhibiteur ('aMK II $_{\text {(281-303) bloque }}$ aussi bien la dégradation induite par la CaMK II tronquée que par l'holoenzyme activée. Ia microinjection de ce peptide supprime également la dégradation des cyclines et l'inactivation de MPF dans l'œuf soumis à un traitement parthénogénétique. Enfin, le décours de l'activation de la ('aMK II $_{\text {endogène, }}$ mesuré par la phosphorylation d'un peptide substrat spécifique de cette enzyme, reflète de façon satisfaisante celui de la vague calcique provoquée par la fécondation.

Le fait troublant est que la C.aMK $_{\text {II }}$ active la dégradation des cyclines et 
l'inactivation de MPF avant l'inactivation de c-Mos et de CSF. Ainsi, non seulement c-Mos n'est pas capable d'empêcher la vague calcique qui suit la fécondation d'activer la protéolyse des cyclines dépendante de l'ubiquitine, mais cette protéolyse pourrait elle-même être la cause, non la conséquence, de l'inactivation de c-Mos et CSF. En absence de c-Mos, les cycles cellulaires de l'embryogenèse précoce se font ensuite sans arrêt métaphasique, l'activation périodique de la voie de dégradation des cyclines par MPF ne nécessitant alors plus de vague calcique semblable à celle qui suit la fécondation (voir figure 1).

Le hasard fait ainsi que, quatrevingts ans après les travaux pionniers du montpelliérain Eugène Bataillon, qui découvrit l'activation parthénogénétique de l'ceuf de xénope par piqûre (provoquant un flux entrant d'ions $\mathrm{Ca}^{2+}$ ), une autre équipe montpelliéraine (en collaboration avec une équipe américaine) identifie aujourd'hui le médiateur du $\mathrm{Ca}^{2+}$ dans la fécondation et la parthénogenèse. Il reste à élucider le mécanisme par lequel la $\mathrm{CaMK}_{11}$ contrôle la voie de dégradation des cyclines et la mise en route de l'embryogenèse.

T.L.

1. Dorée M. Le complexe Cdc2-cycline: un facteur universel pour l'entrée en mitose. mérderine/sciences 1990);6:8-9.

2. Le Peuch (. L La régulation de la division cellulaire. médecine/sciences 1990); 6: 10-7.

3. Sagata N, Watanabe N, Vande Woude GP, Ikawa Y. The c-Mos proto-oncogène product is a cytostatic factor responsible for meiotic arrest in vertebrate eggs. Nature 1989; 342 : $512-8$

4. Felix MA, I abbé JC, Dorée M, Hunt T, Karsenti F. Triggering of cyclin degradation in interphase extracts of amphibian eggs by cdc'2 kinase. Nature 1990); 336: 379-82.

5. Watanabe N, Vande W'oude (;l, Ikana $Y$ Sagata N. Specific proteolysis of the c-Mos proto-oncogene product by calpain at fertiliration of Xenopus eggs. Nature 1989; 342: 50)5-11.

6. Iorca T, (iruzalegui FH, Fesquet I), (avadore JC, Méry J, Means A, Dorée $M$. Calmodulin-dependent protein kinase II mediates inactivation of MPF and (SF upon fertilization of Xenopus eggs. Nature 1993; $366: 27(0-3$.

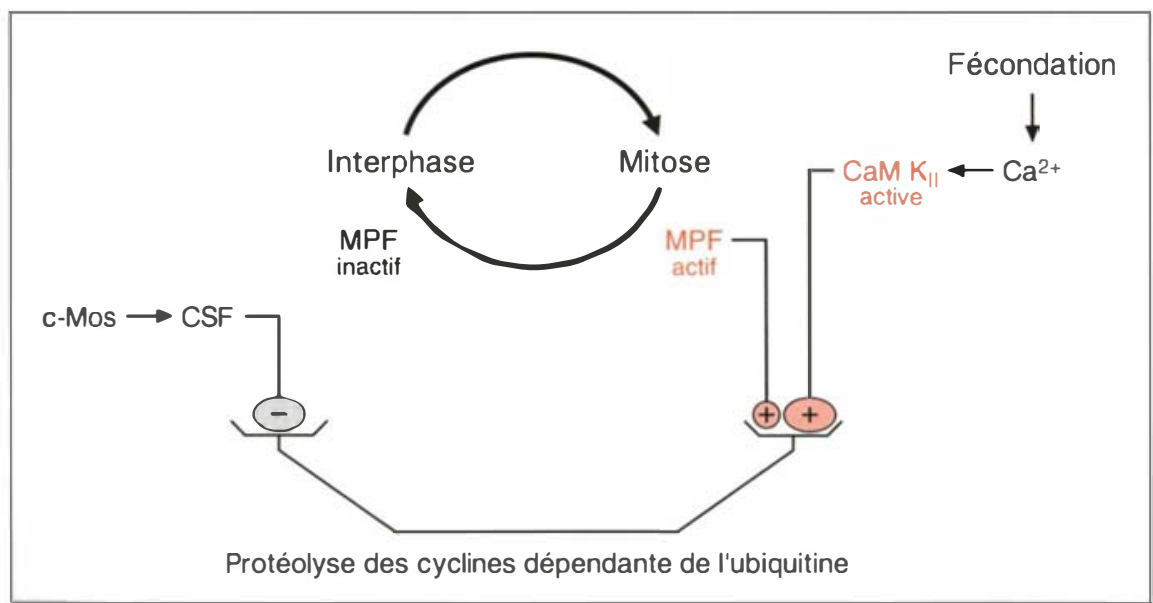

Figure 1. Schéma de l'activation des divisions cellulaires de l'oeuf par le calcium. La dégradation des cyclines, indispensable à l'inactivation du MPF (maturation/mitosis promoting factor), est provoquée par le MPF actif lui-même, mais, dans l'ovocyte, cet effet est bloqué à la métaphase de la seconde division méiotique par le CSF (cytostatic factor) dont l'oncogène cMos est l'un des éléments. Cependant, la vague calcique provoquée par la fécondation active la protéine kinase de type II dépendante de la calmoduline qui aboutit à la dégradation des cyclines, à l'inactivation de l'activité MPF (et, secondairement, de c-Mos/CSF), et ainsi à la reprise du cycle cellulaire. 